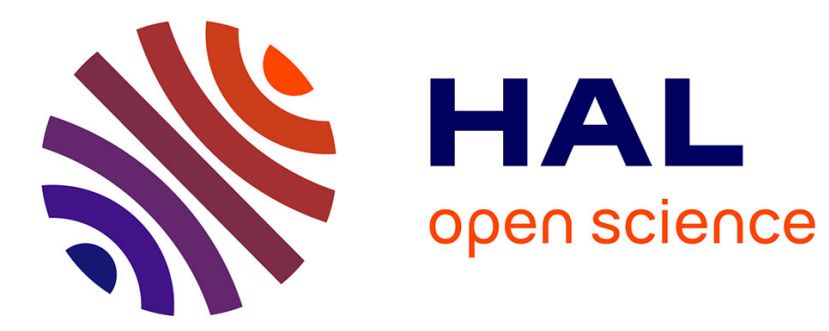

\title{
Optimal Predictive Eco-Driving Cycles for Conventional, Electric, and Hybrid Electric Cars
}

Djamaleddine Maamria, Kristan Gillet, Guillaume Colin, Yann Chamaillard, Cédric Nouillant

\section{- To cite this version:}

Djamaleddine Maamria, Kristan Gillet, Guillaume Colin, Yann Chamaillard, Cédric Nouillant. Optimal Predictive Eco-Driving Cycles for Conventional, Electric, and Hybrid Electric Cars. IEEE Transactions on Vehicular Technology, 2019, 68 (7), pp.6320-6330. 10.1109/TVT.2019.2914256 . hal-02461597

\section{HAL Id: hal-02461597 https://hal.science/hal-02461597}

Submitted on 30 Jan 2020

HAL is a multi-disciplinary open access archive for the deposit and dissemination of scientific research documents, whether they are published or not. The documents may come from teaching and research institutions in France or abroad, or from public or private research centers.
L'archive ouverte pluridisciplinaire HAL, est destinée au dépôt et à la diffusion de documents scientifiques de niveau recherche, publiés ou non, émanant des établissements d'enseignement et de recherche français ou étrangers, des laboratoires publics ou privés. 


\title{
Optimal predictive eco-driving cycles for conventional, electric and hybrid electric cars
}

\author{
D. Maamria ${ }^{a}$, K. Gillet ${ }^{a}$, G. Colin ${ }^{a}$, Y. Chamaillard ${ }^{a}$ and C. Nouillant ${ }^{b}$
}

\begin{abstract}
In this paper, the computation of eco-driving cycles for electric, conventional and hybrid vehicles using receding horizon and optimal control is studied. The problem is formulated as consecutive-optimization problems aiming at minimizing the vehicle energy consumption under traffic and speed constraints. The impact of the look-ahead distance and the optimization frequency on the optimal speed computation is studied to find a trade-off between the optimality and the computation time of the algorithm. For the three architectures considered, simulation results show that in urban driving conditions, a look-ahead distance of $300 \mathrm{~m}$ to $500 \mathrm{~m}$ leads to a sub-optimality less than $1 \%$ in the energy consumption compared to the global solution. For highway driving conditions, a look-ahead distance of $1 \mathrm{~km}$ to $1.5 \mathrm{~km}$ leads to a sub-optimality less than $2 \%$ compared to the global solution.
\end{abstract}

\section{INTRODUCTION}

Nowadays, energy efficiency is increasingly becoming a major concern, and a subject of attention from major international organizations. In the automotive industry, the main research directions towards improving energy efficiency focus on decreasing carbon dioxide $\left(\mathrm{CO}_{2}\right)$ emissions. Engine technology and car performances have improved rapidly thanks to alternative propulsion technologies (hybrid and electric systems) and engine downsizing, while drivers have not adapted their behavior (driving style). Eco-driving can be defined as a multi-criteria optimization problem (fuel consumption, trip duration, drivability, etc.) of various tasks (navigation, guidance, stabilization) under safety constraints [1]-[3]. In other words, the idea of eco-driving is to compute the vehicle speed and gear-box ratio set points that minimize the vehicle energy consumption. The results reported in the literature show the dependance of the energy saving via ecodriving on the nature of the trip. In urban driving conditions, the energy saving may reach $20 \%$ while for highway trips, the energy saving is about 5 to $10 \%$ [3]-[7].

To help the drivers to reduce the energy consumption of their vehicles, a human machine interface (HMI) integrated in the dashboard proposes the optimal speed and gear-box ratio set points to the driver. The computation of these setpoints can be formulated as an optimization problem under constraints such as speed limits, traffic information, the trip duration and the final destination [1], [8]-[10]. Depending on the horizon of the available information, two scenarios are distinguished: Off-line scenario and On-line scenario.

${ }^{a}$ D. Maamria, K. Gillet, G. Colin and Y. Chamaillard are with Univ. Orléans, PRISME, EA 4229, F45072, Orléans, France. djamaleddine.maamria@gmail.com

${ }^{b}$ C. Nouillant is with PSA Peugeot Citroën, Direction Recherche Innovation \& Technologies Avancées (DRIA), France
In the off-line scenario, the constraints (speed limits and traffic information) are fully known in advance. This question was addressed for conventional vehicles in [4], [6], [11], for electric cars in [1], [5], [12], [13] and for hybrid electric cars in [9], [11], [14]-[16]. In this case, an upper bound on energy saving that can be reached through eco-driving, can be computed and used as a reference. In addition, some heuristic rules to reduce the fuel consumption may be extracted from the optimal solutions: anticipate the traffic flow, drive at a low engine speed. The ability to anticipate traffic flow depends on many factors such as the road layout, visibility and it is therefore unreasonable to expect it consistently of a driver. It is necessary to use algorithms to gather data from available sources and help the driver to anticipate.

In the on-line scenario, the future driving conditions are partially known for a given time or distance horizon usually called e-horizon. The information can be retrieved and updated in real time from many sources such as onboard sensors, ADAS (Advanced Driver-Assistance Systems) and navigation systems (Global Positioning System GPS unit). Based on the available information, the optimizer has to find the set points of the vehicle speed and the gear-box ratio in real time to minimize the energy consumption of the vehicle. This question has mainly been studied for heavy duty vehicles (trucks) due to the cost of fuel consumption for haulage companies [17]-[20] where the roadway grade is among the biggest contributors to high fuel consumption. The objective was to find the speed and gear-box ratio set-points that minimize a trade-off between the fuel consumption and the trip duration on a predefined speed range. The studies in [21], [22] deal with an eco-driving system using Model Predictive Control (MPC) within a given prediction horizon for passenger cars in an urban road network with complex traffic flows. The study in [23] highlights the potential of realtime vehicle speed optimization as a mechanism for energy saving. A driver feedback system, designed using Dynamic Programming (DP), was demonstrated in a test vehicle that uses the optimal velocity profile for the upcoming road. The DP algorithm was implemented with a distance step interval of $50 \mathrm{~m}$ and 30 steps in the horizon, giving a total of $1.5 \mathrm{~km}$. The distance step interval of $50 \mathrm{~m}$ from our viewpoint is high (the time needed to travel $50 \mathrm{~m}$ when the vehicle speed is $100 \mathrm{~km} / \mathrm{h}$ is $1.8 \mathrm{~s}$ ) and the choice of a $1.5 \mathrm{~km}$ horizon was chosen arbitrarily.

This paper follows the same approach as the on-line scenario and pushes it further for passenger (conventional, electric and parallel hybrid electric) cars. Depending on the length of the e-horizon, the on-line scenario will lead to a 
sub-optimality in the energy saving with respect to the global optimum (full knowledge of the future driving conditions). By using MPC and DP, the objective is to select the value of the look-ahead horizon in order to minimize the induced suboptimality in the energy saving while keeping the algorithm computation time reasonable. This choice is also interesting to size/choose sensors that predict future driving conditions. For this, various values of the e-horizon are considered and the induced sub-optimality compared to the global optimum is quantified. The choice of the look-ahead distance will be realized based on the optimality/computation time balance.

The paper is organized as follows. In Section II, the vehicle model and the computation of eco-driving cycles for conventional and electric cars are detailed. Section III presents the proposed predictive scheme. Numerical and simulation results are discussed in Section IV. An extension to hybrid electric cars is discussed in Section V. Some conclusions about the algorithm tuning are drawn in light of the presented results.

\section{PROBLEM FORMULATION}

\section{A. Vehicle Modeling [24]}

1) Motion equations: The vehicle is modeled in a vertical plane. According to Newton's law of motion, the vehicle speed $v$ satisfies the following differential equation

$$
m \cdot \frac{d v(t)}{d t}=F_{t}(t)-F_{r}(t),
$$

where $m$ is the total vehicle mass including rotating parts, $F_{t}$ is the traction force provided by the prime mover and $F_{r}$ is the sum of resistance forces including rolling resistance force and aerodynamic drag force. Its expression is $F_{r}(t)=c_{0}+$ $c_{1} \cdot v(t)+c_{2} \cdot v(t)^{2}$, where $c_{i}, i=\{0,1,2\}$ are the coefficients of the road load equation.

2) Prime mover: In the case of a conventional vehicle, the prime mover is an Internal Combustion Engine (ICE). In this study, the ICE is a Diesel engine. Its measured fuel consumption $\dot{m}_{f}(\mathrm{~g} / \mathrm{s})$ is computed through a look-up table as a function of the engine torque $T_{e}$ and the engine speed $\omega_{e}: \dot{m}_{f}\left(\omega_{e}, T_{e}\right)$ (see Figure 1$)^{1}$.

The choice of a Diesel engine is not restrictive as the proposed method can be easily extended to gasoline engines.

In the case of an electric car, the prime mover is an electric machine. It is modeled by a quasi-static map describing the electric power (Figure 2) as a function of the electric machine torque $T_{e}$ and speed $\omega_{e}: P_{m}\left(\omega_{e}, T_{e}\right)$. This measured map usually includes the losses in the electric machine and the power electronic devices.

3) Transmission: The torque $T_{e}$ is related to the driver's torque demand at the wheel $T_{w h}$ by

$$
T_{w h}(t)=r_{\text {tire }} \cdot F_{t}(t)=\eta_{g b} \cdot R_{g b}(t) \cdot R_{t} \cdot T_{e}(t),
$$

${ }^{1}$ The relation between $\dot{m}_{f}(\mathrm{~g} / \mathrm{s})$ and $\mathrm{SFC}(\mathrm{g} / \mathrm{kWh})$ is given by

$$
S F C=\frac{\dot{m}_{f}}{3600 \times \omega_{e} \times T_{e}}
$$

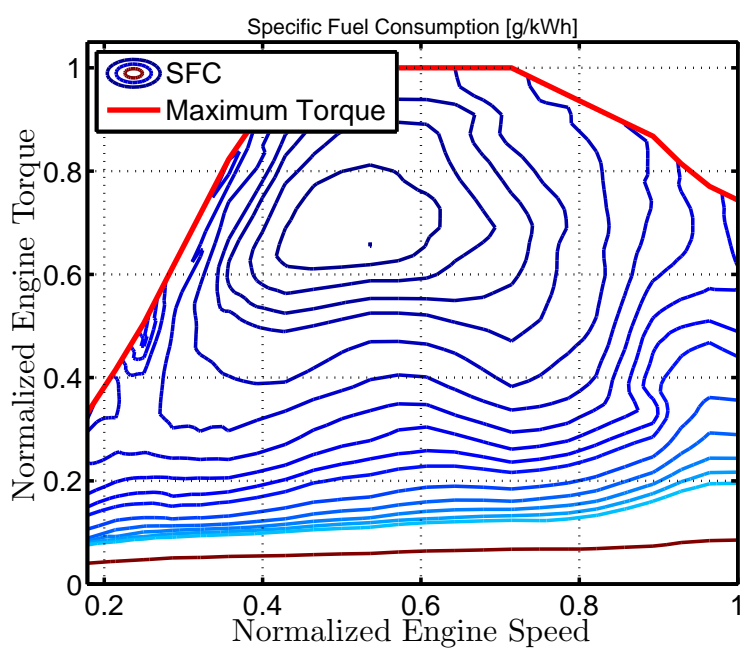

Fig. 1. Specific fuel consumption SFC (g/kWh) of the internal combustion engine as a function of the engine torque and the engine rotational speed. For confidentiality reasons, the data are normalized.

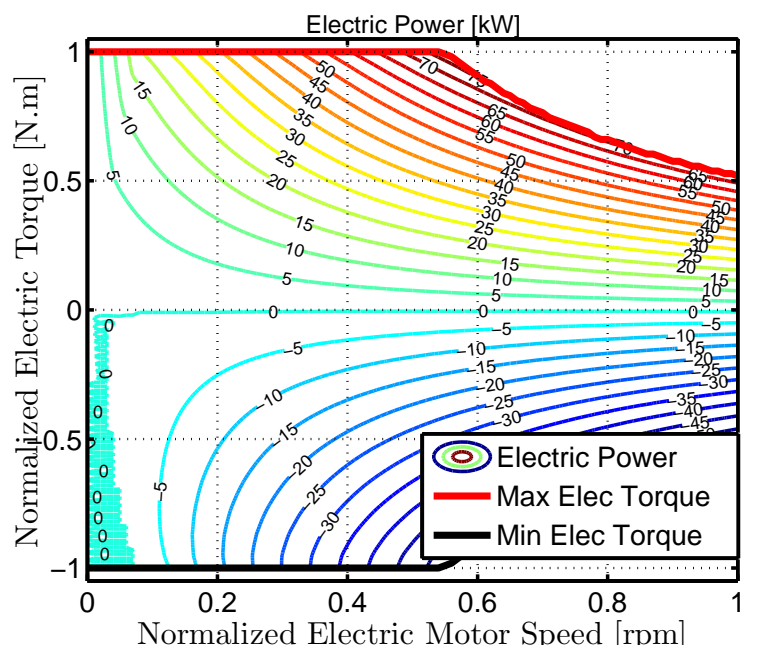

Fig. 2. Electric Machine Power [kW] as a function of the electric machine torque and the rotational speed. For confidentiality reasons, the data are normalized.

where $R_{g b}$ is the gear-box ratio, $\eta_{g b}$ is the gear-box efficiency (assumed to be constant) and $R_{t}$ is the differential ratio. The torque $T_{w h}$ can be positive (traction) or negative (braking). Similarly, the rotational speed $\omega_{e}$ is related to $v$ by

$$
\omega_{e}(t)=R_{g b}(t) \cdot R_{t} \cdot \frac{v(t)}{r_{\text {tire }}} .
$$

4) Battery model: The battery is represented by an equivalent circuit model comprising a voltage source $U_{\text {ocv }}$ in series with an electric resistance $R_{b}$, both of which vary with $\xi$, the battery state of charge (SOC) [24], [25]. The expression of the battery current $I_{b}$ is given by [24]

$I_{b}\left(\xi, v, T_{e}\right)=\frac{1}{2 R_{b}(\xi)}\left(U_{o c v}(\xi)-\sqrt{U_{o c v}^{2}(\xi)-4 R_{b}(\xi) \cdot P_{m}\left(v, T_{e}\right)}\right)$.

Based on the study [13], constant values of $R_{b}$ and $U_{o c v}$ are used: neglecting the dynamics of $\xi$ in the eco-driving 
cycle computation leads to a negligible sub-optimality. The electrochemical battery power is defined by

$$
P_{e c h}=I_{b} \cdot U_{o c v} .
$$

The dynamics of $\xi$ is given by

$$
\frac{d \xi(t)}{d t}=-\frac{I_{b}(t)}{Q_{0}}
$$

where $Q_{0}$ is the nominal battery capacity.

The model parameters are summarized in Table I. The numerical values are omitted for confidentiality reasons.

\section{TABLE I}

VEHICLE MODEL PARAMETERS

\begin{tabular}{|l|l|c|}
\hline Acronym & Description & Unit \\
\hline$m$ & Vehicle mass & $\mathrm{kg}$ \\
$r_{t i r e}$ & Wheel radius & $\mathrm{m}$ \\
$c_{0}$ & Constant coefficient of the road load & $\mathrm{N}$ \\
$c_{1}$ & Linear coefficient of the road load & $\mathrm{N} /(\mathrm{m} / \mathrm{s})$ \\
$c_{2}$ & Quadratic coefficient of the road load & $\mathrm{N} /(\mathrm{m} / \mathrm{s})^{2}$ \\
$\eta_{g b}$ & Gear-box efficiency & - \\
$R_{g b}$ & Gear-box ratio & - \\
$R_{t}$ & Differential ratio & - \\
$Q_{0}$ & Battery capacity & $A . h$ \\
$R_{0}$ & Battery internal resistance & $\Omega$ \\
$U_{o c v}$ & Battery open-circuit voltage & $V$ \\
\hline
\end{tabular}

\section{B. OCP formulation}

The eco-driving approach consists in finding the best vehicle speed profile that minimizes the vehicle energy consumption for a fixed road. The vehicle starts from a point $A$ at a velocity $v_{0}(\geq 0)$ and must reach a destination point $B$ at time $t_{f}$, with a velocity $v_{1}(\geq 0)$. Some constraints have to be considered: acceleration and speed limits, and traffic constraints [5], [10]. This question can be formulated as an Optimal Control Problem (OCP) [1], [10].

The cost function to be minimized is

$$
J=\int_{0}^{t_{f}} L\left(\omega_{e}(t), T_{e}(t)\right) d t
$$

where $t_{f}$ is the trip duration. In the case of a conventional vehicle, $L$ is the fuel consumption $\dot{m}_{f}$ while in the case of an electric car, $L$ is the electrochemical battery power $P_{e c h}$.

The control variable to be optimized $u$ is composed of two components: the torque $T_{e}$ and the gear-box ratio $R_{g b}$

$$
u(t)=\left[T_{e}(t), R_{g b}(t)\right] .
$$

For the electric car, the considered gear-box has one ratio, only the electric machine torque is optimized. This optimization is carried out under the following stable dynamics

$$
\begin{aligned}
\frac{d v(t)}{d t} & =f(v(t), u(t)), & v(0) & =v_{0}, \\
\frac{d x(t)}{d t} & =v(t), & x(0) & =0,
\end{aligned}
$$

where $x$ is the vehicle position and the non-linear function $f$ is calculated by combining $(1,2)$

$$
f=\frac{1}{m}\left(-c_{0}-c_{1} \cdot v-c_{2} \cdot v^{2}+\frac{\eta_{g b}}{r_{\text {tire }}} \cdot R_{g b} \cdot R_{t} \cdot T_{e}\right) .
$$

Since the speed, the torque $T_{e}$ and the gear-box ratio are limited, the final position and speed are fixed, the optimization is performed under the following mixed state and input constraints

$$
\begin{aligned}
v & \in\left[0, v_{\max }(x)\right], \\
f(v, u) & \in\left[a_{\min }, a_{\max }\right], \\
T_{e} & \in\left[T_{\min }\left(\omega_{e}\right), T_{\max }\left(\omega_{e}\right)\right], \\
\omega_{e} & \in\left[\omega_{\min }, \omega_{\max }\right], \\
x\left(t_{f}\right) & =D, \\
v\left(t_{f}\right) & =v_{1},
\end{aligned}
$$

where $v_{\max }(x)$ is the speed limits at the vehicle position $x$, $D$ is the total traveled distance, $v_{1}$ is the desired final speed, $T_{\min }$ and $T_{\max }$ are the minimum and the maximum prime mover torque given by look-up tables as a function of the rotation speed $\omega_{e}$ (see Figures 1 and 2).

Equation (7) limits the vehicle acceleration between its maximum and minimum values. The acceleration is an algebraic function of the vehicle speed and the control variables. This function can be evaluated for all the possible choices of the vehicle speed and the control variables. The values not satisfying the constraints are excluded. The constraints on the prime mover torque in (8) and the rotational speed in (9) are mixed input-state constraints, they depend on the vehicle speed $v$ and the gear-box ratio $R_{g b}$.

In this paper, the torque converter dynamics is not considered in the OCP formulation because it increases the complexity of the optimization problem (thus the computation time) and the experimental and simulation results are very close [6]. To summarize, the OCP is

$$
(O C P): \min _{u} \int_{0}^{t_{f}} L(v, u) d t
$$

under the dynamics $(4,5)$, the state and input constraints $(6,7,8,9)$, and the final constraints $(10,11)$. Thus, the optimized vehicle speed trajectory can be computed using (4) once the control variable $u$ is optimized and the initial condition of the vehicle speed is known.

1) Speed limits: To specify the speed limits $v_{\max }$, a certain (fixed) margin $e_{l}(>0)$ on the initial driving cycle speed is considered

$$
v_{\max }(x)= \begin{cases}v_{r e f}(x)+e_{l}, & v_{\text {ref }}(x)>0, \\ 0, & v_{\text {ref }}(x)=0,\end{cases}
$$

where $v_{r e f}(x)$ is the speed value of the initial driving cycle at the position $x$ which is used as a reference of comparison to point out the benefit of eco-driving in terms of fuel consumption reduction. Note that the eco-driving cycle must have the same number of stops as the initial driving cycle [10].

Other methods to compute speed limits can be considered [4], [14]. For example, the speed limits can be given by the traffic signs or provided by a cloud server depending on the vehicle position. The choice of method used to compute the speed limits does not impact the solving method. 
2) Solving method: The (OCP) defined in (12) can be solved using several methods: Pontryagin Minimum Principal (PMP) or Dynamic Programming (DP). Because of the non-linear nature of the optimization problem and the mixed state-input constraints, methods based on PMP are more complicated to implement [26]. Thus, the method proposed here is based on Dynamic Programming [27], [28].

To reduce the computation time, the chosen approach transforms a time-based OCP into a distance-based OCP while introducing an additional term in the cost function as suggested in [2], [4]. If the position space is discretized in $N$ fixed steps of length $\Delta x$, the time step $\Delta t(k), k=1: N$ is variable and is calculated from the vehicle speed $v(k)$ and the acceleration $a(k)$ by solving the following equation [4]

$$
\Delta x=\frac{1}{2} a(k) \cdot \Delta t(k)^{2}+v(k) \cdot \Delta t(k) .
$$

The final constraint on the vehicle position (10) is fulfilled by construction: the total traveled distance is $D=N \cdot \Delta x$. The trip duration is given by $t_{f}=\sum_{i=1}^{N} \Delta t(i)$. To control $t_{f}$, an additional tunable term $\beta \cdot \Delta t(k)$ is added to the cost function [2] as follows

$$
\bar{J}_{s}(u)=\sum_{k=1}^{k=N}[L(v(k), u(k))+\beta] \Delta t(k),
$$

where the constant tunable parameter $\beta$ penalizes the final time to obtain almost the same time duration as the initial driving cycle. The tuning of this parameter is discussed in the next paragraph.

3) Estimation of $\beta$ : The parameter $\beta$ is introduced to penalize the trip duration $t_{f}$. This parameter is usually tuned iteratively [1], [4]. The objective here is to estimate heuristically the value of $\beta$ from the initial trip characteristics while keeping the error on the final time acceptable.

For this purpose, various driving cycles are used. The relation between $\beta$ (searched iteratively) and the mean speed value $\bar{v}$ of the driving cycles (which is global information of the trip) is studied. The results in the case of the electric car for two values of $e_{l}$ are summarized in Figure 3.

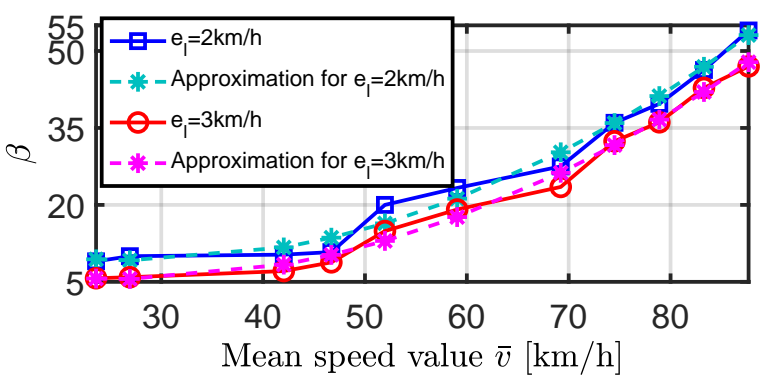

Fig. 3. Relation between $\beta$ and the mean speed value $\bar{v}$ : Electric case.

For a fixed value of $e_{l}$, the relation between $\beta$ and $\bar{v}$ is monotone: $\beta$ increases when $\bar{v}$ increases. This heuristic relation can be approximated by a quadratic form (dashed curves in Figure 3) as follows

$$
\beta=\alpha_{2} \cdot \bar{v}^{2}+\alpha_{1} \cdot \bar{v}+\alpha_{0},
$$

where $\alpha_{i}, i=\{0,1,2\}$ have to be identified. These parameters depend on the vehicle characteristics such as the weight and the coefficients of the road load equation. In addition, for the same value of $\bar{v}, \beta$ increases when $e_{l}$ decreases.

To validate the proposed relation to estimate $\beta$, the error on the final time for various driving cycles is given in Table II. The Artemis Highway [29] and WLTC (the Worldwide harmonized Light vehicles Test Cycle) are two normalized driving cycles. The driving cycles 1 and 2 are real-driving cycles provided by the French car manufacturer PSA.

TABLE II

ERROR ON THE FINAL TIME WITH THE VALUES OF $\beta$ COMPUTED USING (13): ELECTRIC CASE

\begin{tabular}{|l|c|c|c|c|}
\hline Driving Cycle & Cycle 1 & Cycle 2 & A. Highway & WLTC \\
\hline$t_{f}[s]$ & 5787 & 2432 & 1043 & 1574 \\
\hline Error on $t_{f}[\%]: e_{l}=2$ & $2.7 \%$ & $-3.9 \%$ & $-1.6 \%$ & $1.6 \%$ \\
\hline
\end{tabular}

The error on the final time is less than $3.9 \%$, which is considered acceptable as the value of $\beta$ is only estimated based on the mean speed value of the trip. The same approach is used for the conventional vehicle and the results are similar: the error on the final time is less than $4 \%$.

The heuristic relation between $\beta$ and the trip mean speed value simplifies the tuning procedure of $\beta$ by providing a first good guess of its value and thus restricting the research field. This relation will be more useful for an embedded version of the proposed algorithm where the computation time and the number of iterations to find $\beta$ have to be reduced.

\section{PREDICTIVE ECO-DRIVING CYCLE COMPUTATION}

It is well-known that control strategies obtained by optimal control use the full knowledge of the future (speed limits and traffic information in this study). However, these future conditions are uncertain and not totally known in advance in real situations. They may change in time and they depend on many factors such as local traffic, infrastructure status, non-vehicle actors and weather conditions. To deal with this situation, Model Predictive Control (MPC) techniques can be used [30]-[32].

\section{A. Principle}

The idea of the suggested method is the following: the future driving conditions are only known for a look-ahead distance $D_{0} \leq D$ and the speed trajectory will be recalculated every traveled distance $D_{f}$ called optimization frequency where $D_{f}<D_{0}$. The total traveled distance $D$ is divided into $n$ intervals $D_{i}, i=0: n-1$ where $n$ is the ratio between $D$ and $D_{f}$. The OCP in (12) will be solved $n$ times

$$
\left(O C P_{i}\right): \min _{u} \int_{t_{i}}^{t_{i+1}} L(v, u) d t
$$

under the dynamics $(4,5)$, the state and input constraints $(6,7,8,9)$. The time $t_{i}$ corresponds to the moment when the vehicle reaches the position $\left(i \cdot D_{f}\right)$ while the time $t_{i+1}$ corresponds to the moment for the position $\left(i \cdot D_{f}+D_{0}\right)$. Thus, the constraints on the vehicle position are

$$
x\left(t_{i}\right)=i \cdot D_{f}, \quad x\left(t_{i+1}\right)=i \cdot D_{f}+D_{0} .
$$


For $i=n-1$, the vehicle position will be $(n-1) \cdot D_{f}+D_{0}$. If this position is greater than $D$, the look-ahead horizon will be only $D-(n-1) \cdot D_{f} \leq D_{0}$.

As the future speed limits are only known for $D_{0}$, vehicle speed is free at the end of each segment $\left(i \cdot D_{f}+D_{0}\right)$ except for the last segment

$$
v\left(t_{n}\right)=v_{1},
$$

where $v_{1}$ is the desired final speed at the end of the trip. Usually, this value is null, as it corresponds to a vehicle stop. This choice simplifies the algorithm as it is difficult to compute the appropriate speed at the position $\left(i \cdot D_{f}+D_{0}\right)$.

The optimization scheme is illustrated in Figure 4. The optimization problem for a total traveled distance of $D$ is divided into $n$ sub-problems solved successively. At each traveled distance $D_{f}$, the speed limits and the traffic information are updated. A new vehicle speed trajectory is calculated on a distance horizon $D_{0}$ by solving the OCP (14) using the method described in Section (II-B.2). The speed trajectory obtained has to be followed by the driver. To avoid the effects due to human interaction, the vehicle is assumed to follow the speed set points precisely (in simulation).

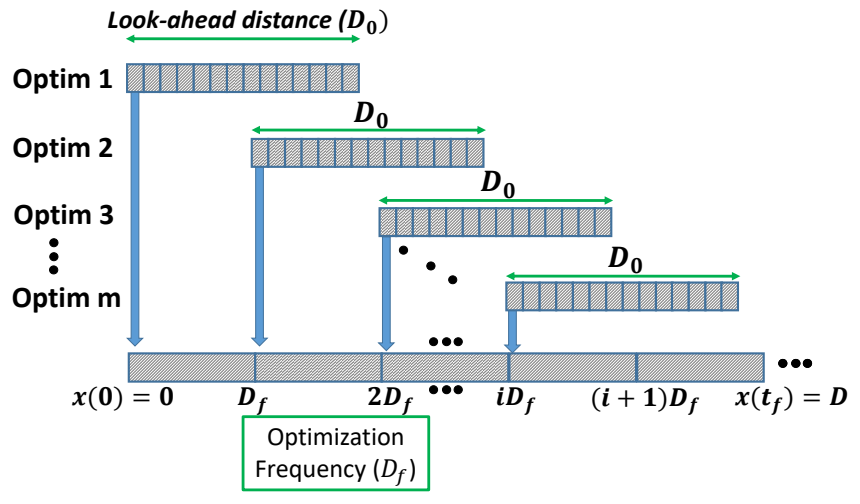

Fig. 4. Predictive algorithm scheme for eco-driving.

\section{B. Choice of $D_{f}$}

The optimality of the algorithm described in the previous section depends on the choice of $D_{0}$ and mainly on $D_{f}$. The choice of $D_{0}$ depends on the information that can be gathered from the available sources (GPS and vehicle sensors). In this paper, for various values of $D_{0}$, the choice of $D_{f}$ is optimized to find the best trade-off between the optimality and the implementation constraints of the algorithm.

- The value of $D_{f}$ must be greater than a lower bound $D_{f, \min }$ defined by the traveled distance needed to solve the optimization problem (14) (real-time computation constraint). The value of this distance depends on the value of $D_{0}$, the equipment used (hardware) for computing and the available computation time: $D_{f, \min }$ increases when $D_{0}$ increases. $D_{f, \min }$ depends also on the vehicle speed: a low (respectively high) computation time for low (respectively high) mean speed value driving cycles. Thus, $D_{f, \min }$ will be chosen for highway driving cycles. In this study, $D_{f, \min }$ is $100 \mathrm{~m}$.
- An upper bound $D_{f, \max }$ on $D_{f}$ is computed based on the optimality. The methodology is the following: for a given value of $D_{0}$ and for a fixed trip duration $t_{f}$, the value of $D_{f}$ is decreased from $D_{0}$ until $D_{f, \min }$. The suboptimality is computed. Figure 5 shows the extra-fuel consumption and the variation of $\beta$ for various values of $D_{f}$ when $D_{0}=2 \mathrm{~km}$ ( $\beta$ is tuned to get a constant trip duration):

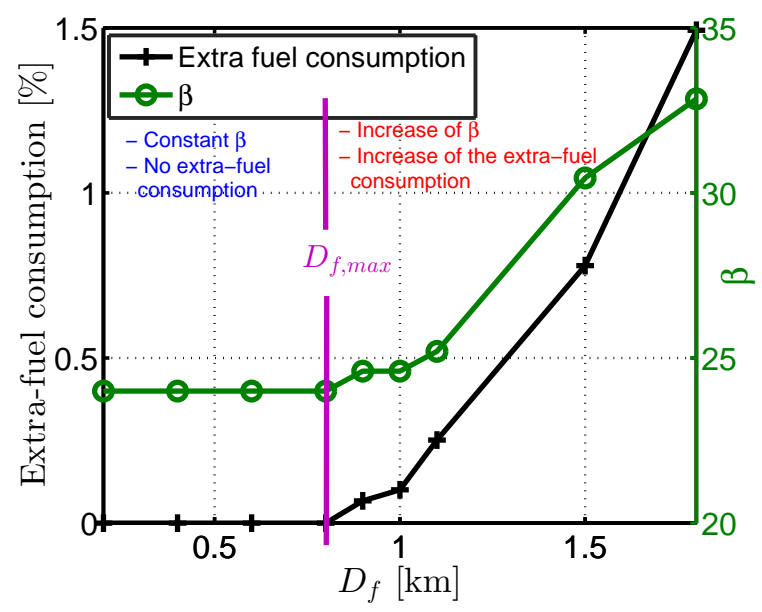

Fig. 5. Sub-optimality and $\beta$ for various values of $D_{f}[\mathrm{~km}]$ for $D_{0}=2 \mathrm{~km}$.

- Optimality is conserved for $D_{f} \leq D_{f, \max }$ : the solution is still optimal with a constant value of $\beta$.

- Sub-optimality increases for $D_{f}>D_{f, \max }$ : the suboptimality solution increases when $D_{f}$ tends to $D_{0}$.

In a distance window of length $D_{0}$, the traffic constraints and speed limits are checked periodically: if there is a modification in the traffic constraints, the optimization is relaunched. By this choice, the use of the Electronic Control Unit (ECU) will be reduced as the optimization is performed only when it is necessary. Obviously, the optimization can be restarted every $D_{f, \min }$, but the ECU will be constantly used. This behaviour increases the electric energy consumed by the ECU and thus increases the energy consumption.

\section{NUMERICAL ILLUSTRATION}

To illustrate the proposed algorithm, five normalized driving cycles are used: ECE-15 (Urban Driving Cycle UDC), EUDC (Extra-urban driving cycle), WLTC (Worldwide harmonized Light vehicles Test Cycle), the Artemis Urban and Artemis Rural driving cycle [29]. The duration $t_{f}$ without stop phases, the total traveled distance $D$, the final SOC (for the electric car) and the fuel consumption (for the conventional case) for each initial driving cycle (vehicle speed $=v_{r e f}$ ) are given in Table III. The considered gearbox has 6 ratios for the conventional vehicle. The value of $e_{l}$ is arbitrarily fixed to $2 \mathrm{~km} / \mathrm{h}$.

A standard computer equipped with an Intel Core i5-4590, CPU $3.30 \mathrm{GHz}$ with $8 \mathrm{~GB}$ of RAM is used. Six scenarios are tested with the values of the look-ahead distance $D_{0}$ and the value of $D_{f}$ given in Table IV. 
TABLE III

INITIAL DRIVING CYCLES CHARACTERISTICS

\begin{tabular}{|l|c|c|c|c|}
\hline Driving Cycle & $t_{f}[\mathrm{~s}]$ & $D[\mathrm{~km}]$ & $S O C\left(t_{f}\right)[\%]$ & Consumption $[\mathrm{g}]$ \\
\hline ECE-15 & 540 & 4 & 83.89 & 202.3 \\
\hline Artemis Urban & 682 & 4.5 & 79.95 & 215.7 \\
\hline Artemis Rural & 1053 & 17.3 & 54.16 & 742 \\
\hline WLTC & 1574 & 22.7 & 37.26 & 973.3 \\
\hline EUDC & 360 & 6.9 & 75.01 & 299.6 \\
\hline
\end{tabular}

TABLE IV

$D_{0}[\mathrm{KM}]$ AND $D_{f}[\mathrm{KM}]$ FOR THE VARIOUS SCENARIOS

\begin{tabular}{|c|c|c|c|c|c|c|}
\hline Scenario & $I$ & $I I$ & $I I I$ & $I V$ & $V$ & $V I$ \\
\hline$D_{0}[\mathrm{~km}]$ & $D$ & 3 & 2 & 1.5 & 1 & 0.5 \\
\hline$D_{f}[\mathrm{~km}]$ & $D$ & 1.9 & 0.9 & 0.34 & 0.26 & 0.14 \\
\hline
\end{tabular}

The values of $D_{f}$ were identified from a driving cycle of $6 \mathrm{~km}$ with only one speed limit at $90 \mathrm{~km} / \mathrm{h}$ : an acceleration from $0 \mathrm{~km} / \mathrm{h}$, a stabilized speed around $80 \mathrm{~km} / \mathrm{h}$ and a deceleration to $0 \mathrm{~km} / \mathrm{h}$. The identification was done for the electric and conventional vehicles. The values of $D_{f}$ for the conventional vehicle were lower than the values of the electric case. The minimum value between the two cases is taken. Scenario $I$ is considered as a reference of comparison (global optimum) in this study as the look-ahead distance $D_{0}$ equals the total traveled distance: full knowledge of the future driving constraints.

For the DP, a distance step of $\Delta x=10 \mathrm{~m}$ is used in the case of the ECE and the A. Urban and $\Delta x=20 \mathrm{~m}$ for the other driving cycles. These values of $\Delta x$ were chosen so as to have a time step approximately around 1s [33]. Two cases are studied: electric and conventional.

\section{A. Case of an electric car}

The cost function $L$ is the electrochemical battery power $P_{e c h}$. The control variable is the electric machine torque $T_{e}$. The following DP mesh parameters are used: $\Delta v=0.02 \mathrm{~m} / \mathrm{s}$ for the vehicle speed and $\Delta T_{e}=2 \mathrm{~N}$.m For the electric machine torque. A sensitivity study using many driving cycles has been conducted to choose the best values of the quantization $\left(\Delta v\right.$ and $\left.\Delta T_{e}\right)$. The criterion was to find a tradeoff between the solution optimality and its computation time. The initial value of the SOC is $90 \%$.

For scenario $I$, the results in terms of energy consumption, energy saving through eco-driving with respect to the initial driving cycles and computation time $t_{c o}$ are given in Table V.

TABLE V

RESULTS OF SCENARIO I (GLOBAL OPTIMUM) IN TERMS OF FUEL CONSUMPTION, FUEL SAVING COMPARED TO THE INITIAL DRIVING CYCLES AND THE COMPUTATION TIME: ELECTRIC CASE

\begin{tabular}{|l|c|c|c|}
\hline & $S O C\left(t_{f}\right)[\%]$ & Energy reduction [\%] & $t_{c o}[\mathrm{~s}]$ \\
\hline ECE-15 & 85.09 & 19.6 & 3.5 \\
\hline A. Urban & 84.63 & 46 & 4.6 \\
\hline A. Rural & 59.74 & 15.6 & 16.2 \\
\hline WLTC & 50.29 & 24.7 & 24.3 \\
\hline EUDC & 76.86 & 12.3 & 6.8 \\
\hline
\end{tabular}

The extra-energy consumption and the error on the final time $t_{f}$ with respect to scenario $I$ are given in Figure 6. For each cycle, the results are obtained using the same value of $\beta$ calculated by (13).

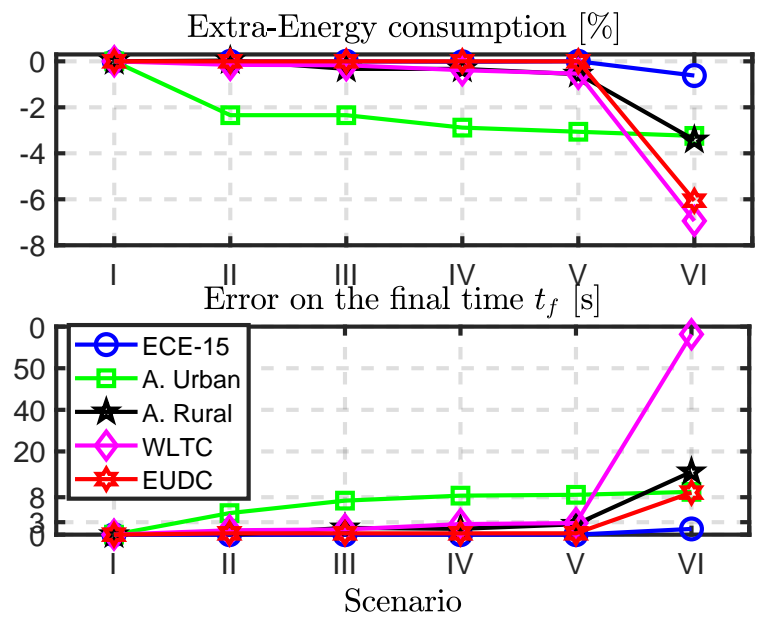

Fig. 6. Extra-energy consumption [\%] and the error on the final time $[s]$ versus scenarios of Table IV: Electric case.

For each scenario from Table IV, a positive value of the error on $t_{f}$ means that the trip duration obtained is greater than its value for scenario $I$. The consequence of that is a decrease in the energy consumption (as can be seen from the negative values of the extra-energy consumption in Figure 6). These results show that the trip duration $t_{f}$ increases slowly with a maximum error of $3 \mathrm{~s}$ when $D_{0}$ decreases until $1 \mathrm{~km}$ except for the Artemis urban case where the error is about $8 \mathrm{~s}$. When $D_{0}=0.5 \mathrm{~km}$, the error on $t_{f}$ increases significantly: $3 \%$ of the total time in the WLTC case. At the same time, the energy consumption decreases.

To make a fair comparison between the various scenarios, the corrected extra-energy consumption with respect to scenario $I$ is given in Figure 7. The correction of the energy consumption is calculated to take into account the difference in the trip duration as follows:

corrected energy consumption $=$ energy consumption $-\beta \cdot \Delta t_{f}$,

where $\Delta t_{f}$ is the difference between the obtained final time and its target value.

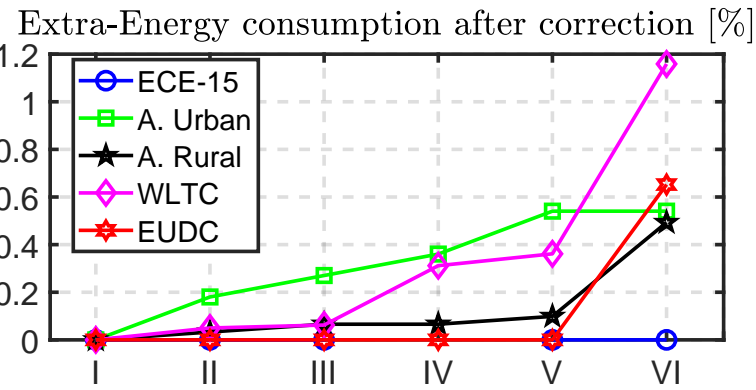

Fig. 7. Corrected extra-energy consumption [\%] versus scenarios of Table IV: Electric case. 
From Figure 7, the induced sub-optimality increases when the look ahead distance $D_{0}$ decreases, and its maximum value is less than $1.2 \%$. This sub-optimality reduces the energy saving of eco-driving to $11.2 \%$ for the EUDC (see Table V). Two cases are distinguished:

- Driving cycles with a low mean speed value (ECE-15 and A. Urban): the sub-optimality is lower than $0.6 \%$.

- Driving cycles with a high mean speed value (A. Rural, WLTC and EUDC): scenario $V$, where sub-optimality is lower than $0.4 \%$, is considered as a good choice.

The vehicle speed trajectories for the EUDC with a constant value of $\beta$ are given in Figure 8 . For $D_{0} \geq 1 \mathrm{~km}$, the speed trajectories are identical. When $D_{0}<1 \mathrm{~km}$, drops appear in the vehicle speed trajectory because the vehicle speed is free at the end of each iteration as explained in Section III-A. That is why in some cases, the value of $\beta$ needs to be adjusted. For this kind of cycle with high vehicle speed, the problem of speed drops appears when $D_{0} \leq 1 \mathrm{~km}$ even if $D_{f}=\Delta x$ (not possible because of the implementation constraint on the choice of $D_{f}$ ).

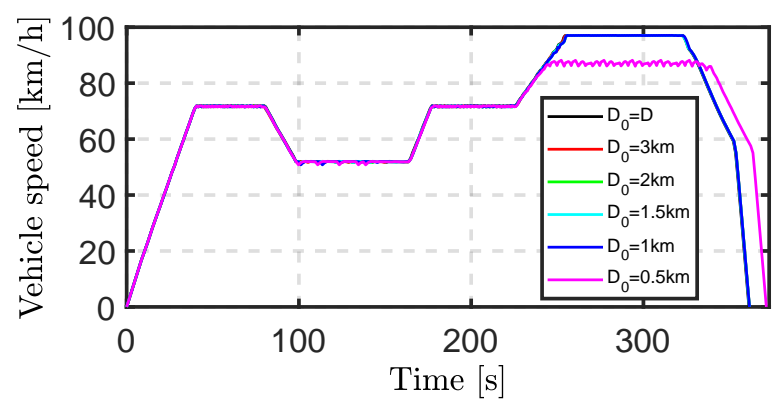

Fig. 8. Speed versus time for the EUDC: Conventional case.

The mean computation time for each optimization and the number of optimizations for the various scenarios are given in Table VI. These values represent the mean time needed to get the new trajectory for a distance window of length $D_{0}$. The computation time is approximately constant for each

TABLE VI

MEAN COMPUTATION TIME [S] FOR EACH OPTIMIZATION AND THE NUMBER OF OPTIMIZATIONS $n$ (BETWEEN BRACKETS) FOR THE VARIOUS SCENARIOS: ELECTRIC CASE

\begin{tabular}{|l|c|c|c|c|c|}
\hline & $I I$ & $I I I$ & $I V$ & $V$ & $V I$ \\
\hline ECE-15 & $1.8(3)$ & $1.2(5)$ & $1.1(12)$ & $0.7(16)$ & $0.4(29)$ \\
\hline A. Urban & $1.7(3)$ & $1.4(5)$ & $1.1(14)$ & $0.8(18)$ & $0.4(33)$ \\
\hline A. Rural & $1.6(10)$ & $1.1(20)$ & $0.8(51)$ & $0.5(67)$ & $0.3(124)$ \\
\hline WLTC & $1.9(12)$ & $1.2(26)$ & $0.8(67)$ & $0.5(88)$ & $0.3(163)$ \\
\hline EUDC & $1.8(4)$ & $1.2(8)$ & $0.7(21)$ & $0.4(27)$ & $0.2(50)$ \\
\hline
\end{tabular}

scenario (in the same column): the computation time per iteration for scenarios $V$ (for the EUDC, the A. Rural and the WLTC) and VI (for the ECE-15 and the A. Urban) is $0.5 \mathrm{~s}$ in the worst case. On the other hand, the overall computation time for the various scenarios increases (in the same row): to get the overall computation time, multiply the number of iterations by the mean time.

\section{B. Case of a Conventional vehicle}

The cost function $L$ to be minimized is the fuel consumption $\dot{m}_{f}$. The control variables are the engine torque $T_{e}$ and the gear-box ratio $R_{g b}$. The following DP mesh parameters are chosen based on the results presented in [33]: $\Delta v=0.1 \mathrm{~m} / \mathrm{s}$ for the vehicle speed and $\Delta T_{e}=2 \mathrm{~N} . \mathrm{m}$ for the engine torque ${ }^{2}$. For scenario $I$, the results in terms of fuel consumption, fuel saving through eco-driving with respect to the initial driving cycles and computation time of the DP $t_{c o}$ are given in Table VII.

TABLE VII

RESULTS OF SCENARIO I (GLOBAL OPTIMUM) IN TERMS OF FUEL CONSUMPTION, FUEL SAVING COMPARED TO THE INITIAL DRIVING CYCLES AND THE COMPUTATION TIME: CONVENTIONAL CASE

\begin{tabular}{|l|c|c|c|}
\hline & Fuel Consumption [g] & Fuel saving [\%] & $t_{c o}[\mathrm{~s}]$ \\
\hline ECE-15 & 125.6 & 37.9 & 5.8 \\
\hline A. Urban & 140 & 35.1 & 7.6 \\
\hline A. Rural & 592.3 & 19.9 & 27.1 \\
\hline WLTC & 755.9 & 22.3 & 41 \\
\hline EUDC & 246.2 & 17.8 & 11.5 \\
\hline
\end{tabular}

As for the electric case, to make a fair comparison between the various scenarios, the corrected extra-fuel consumption with respect to scenario $I$ is given in Figure 9. The correction is introduced to make up the difference in the trip duration:

corrected fuel consumption $=$ fuel consumption $-\beta \cdot \Delta t_{f}$,

where $\Delta t_{f}$ is the difference between the obtained final time and its target value. The extra-fuel consumption induced by the predictive scheme reduces the fuel saving of eco-driving in Table VII: for scenario VI, the fuel saving with respect to the initial driving cycle is reduced to $14.5 \%$ in the case of the EUDC.

Extra-fuel consumption after correction [\%]

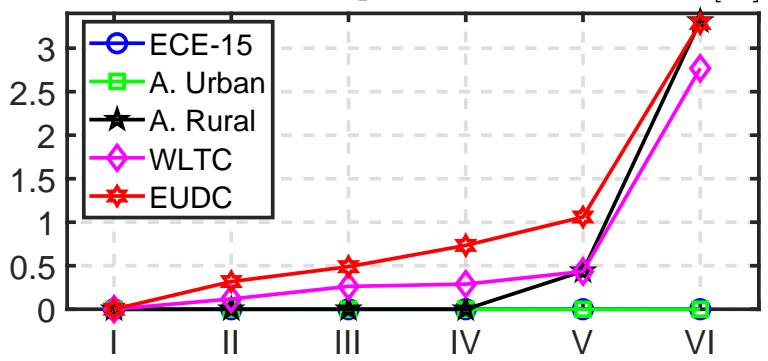

Fig. 9. Corrected extra-fuel consumption [\%] versus scenarios of Table IV: Conventional case.

The extra-fuel consumption increases when the look ahead distance $D_{0}$ decreases. In the case of the ECE-15 and the Artemis Urban, the maximum sub-optimality is less than $0.1 \%$ for all the scenarios considered. The sub-optimality reaches $0.4 \%$ for $D_{0}=0.3 \mathrm{~km}$ and $D_{f}=0.1 \mathrm{~km}$ for these

\footnotetext{
${ }^{2}$ A sensitivity study using many driving cycles has been conducted to choose the best values of $\Delta v$ and $\Delta T_{e}$ to find a trade-off between the solution optimality and its computation time: with the chosen parameters, the computation time is divided by 15 while the sub-optimality is lower than $0.5 \%$ comparing to the case with $\Delta v=0.01 \mathrm{~m} / \mathrm{s}$ and $\Delta T_{e}=1 \mathrm{~N} . \mathrm{m}$.
} 
two driving cycles. In the case of the Artemis Rural, the WLTC and the EUDC, the sub-optimality is less than $1 \%$ for scenario $V$.

The vehicle speed trajectories versus distance for the Artemis Urban are given in Figure 10. The trajectories are identical.

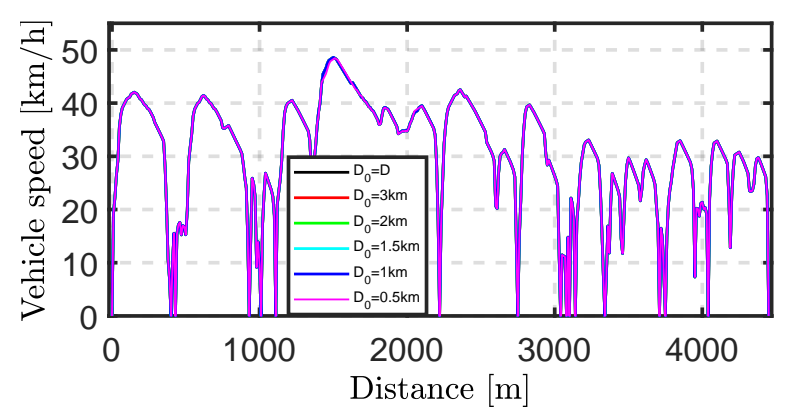

Fig. 10. Speed versus distance for the A. Urban: Conventional case.

The number of optimizations $n$ and the mean computation time for each optimization for the various scenarios are given in Table VIII. The computation time for scenarios $V$ (the

TABLE VIII

MEAN COMPUTATION TIME [S] FOR EACH OPTIMIZATION AND THE NUMBER OF OPTIMIZATIONS $n$ (BETWEEN BRACKETS) FOR THE VARIOUS SCENARIOS: CONVENTIONAL CASE

\begin{tabular}{|l|c|c|c|c|c|}
\hline & $I I$ & $I I I$ & $I V$ & $V$ & $V I$ \\
\hline ECE-15 & $3(3)$ & $2.6(5)$ & $2(12)$ & $1.4(16)$ & $0.8(29)$ \\
\hline A. Urban & $3.8(3)$ & $3.1(5)$ & $2.2(14)$ & $1.6(18)$ & $0.8(33)$ \\
\hline A. Rural & $3.8(10)$ & $2.6(20)$ & $1.9(51)$ & $1.2(67)$ & $0.6(124)$ \\
\hline WLTC & $4.1(12)$ & $2.4(26)$ & $1.6(67)$ & $1.1(88)$ & $0.5(163)$ \\
\hline EUDC & $4.1(4)$ & $2.2(8)$ & $1.5(21)$ & $1(27)$ & $0.5(50)$ \\
\hline
\end{tabular}

EUDC, the A. Rural and the WLTC cases) and VI: the ECE15 and the A. Urban cases) is less than $1.2 \mathrm{~s}$ in the worst case (the time needed to travel $34 \mathrm{~m}$ if the vehicle speed is $100 \mathrm{~km} / \mathrm{h})$.

These results for the electric and the conventional cases show that it is possible to compute eco-driving cycles in a reasonable time (1.2s in the worst case) with a partial knowledge of the future driving constraints and a quasioptimal energy consumption. These promising results are a first step toward the implementation of the eco-driving algorithm in an Engine Control Unit (ECU). A possible extension to hybrid cars is discussed in the next section.

\section{EXTENSION TO THE HYBRID ELECTRIC VEHICLES}

\section{A. Architecture description}

The system considered here is a dual shaft parallel mild hybrid with an electric machine of $12 \mathrm{~kW}$ connected to the Diesel engine described in Section II-A.2 by a belt (Figure 11). The gearbox is between the power-train and the wheel. Due to the choice of architecture:

- for a given gear-box ratio, the engine's speed and the electric machine's speed are dependent,

- during the ZEV mode, the engine injection is cut off and the electric machine keeps the engine rotating.
For more details about this architecture, see [34], [35].

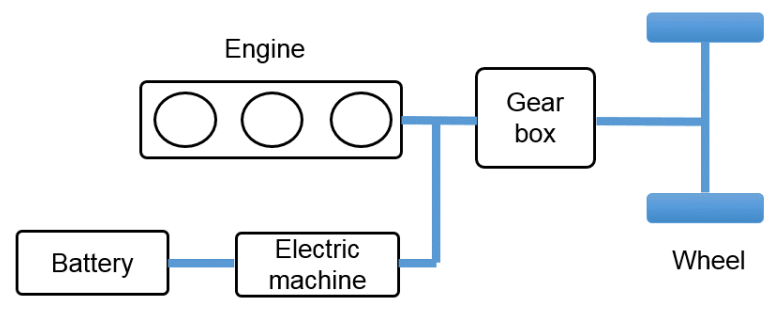

Fig. 11. Parallel mild-hybrid architecture.

For the transmission, the engine torque $T_{\text {eng }}$ and the electric machine torque $T_{e l}$ are related to the torque required at the wheel $T_{w h}$ by

$$
T_{w h}(t)=\eta_{g b} \cdot R_{g b}(t) \cdot R_{t} \cdot\left[T_{e n g}(t)+R_{e l} \cdot T_{e l}(t)\right],
$$

where $R_{e l}$ is the constant motor-to-wheel transmission ratio. Similarly, the engine and the electric machine rotating speeds are linked by

$$
\omega_{e l}(t)=R_{e l} \cdot \omega_{e n g}(t) .
$$

\section{B. Eco-driving cycle computation: Off-line solution}

The simplified approach suggested in [36] for HEV is used as its induced sub-optimality with respect to the optimal solution is small $(<4 \%)$ while its computation time is reasonable. The method involves two steps:

1) Step 1: An eco-driving cycle is calculated assuming that the vehicle is only propelled by the ICE (the vehicle parameters such as the weight and the road load coefficients do not change). The associated OCP is given in equation (12).

2) Step2: An energy management strategy (torque split) is calculated using dynamic programming. The vehicle is assumed to follow the eco-driving cycle obtained in Step1. The duration of the trip was fixed in the previous step. The control variable is the engine torque $T_{\text {eng }}$. As the torque $T_{w h}$ is imposed (the vehicle follows a pre-defined driving cycle with a predefined gear-box ratios), the electric machine torque $T_{e l}$ is calculated from the torque balance in (15). A final constraint on the SOC is imposed. The formulation of this optimization problem was addressed in [24], [37]

A similar approach was used in [11], [36] where the second step was performed using the Pontryagin Minimum Principle (PMP) [38].

As the two steps are decoupled, other methods to design the energy management strategy can be used: for example, the well-known ECMS (Equivalent Consumption Minimization Strategy) [39]-[42] or any other heuristic strategy.

\section{Predictive Eco-driving cycle computation}

In a first step, the method described in Section III-A to compute an eco-driving cycle for a conventional vehicle is used. Next, an energy management strategy is designed. For this, the driving cycle to be followed is only known for a look-ahead distance $D_{0}$. The optimization will be done every 
traveled distance $D_{f}$. The values of $D_{0}$ and $D_{f}$ given in Table IV are used.

As is commonly done for an HEV, a final constraint on the SOC is imposed in order to make a fair comparison between optimization strategies. A sustaining final constraint on the SOC will be imposed at the end of each segment:

$$
\xi\left(t_{i+1}\right)=\xi\left(t_{i}\right)=\xi_{r e f},
$$

where $\xi_{\text {ref }}$ is the desired final SOC. Only the trajectory of $\xi$ on a distance window of length $D_{f}$ is considered: the SOC does not come back to its target final value at the end of each traveled distance $D_{f}$.

\section{Numerical Results}

The computation of an eco-driving cycle for HEV is done in the two steps described in Section V-B. The values of $D_{f}$ in Table IV are used for the two steps. For the first step, the DP mesh parameters are the same as in Section IV-B. For the energy management strategy computation, the following mesh parameters are used: $\Delta \xi=0.025 \%$ for the SOC and a step of 2 N.m for the engine torque.

The fuel consumption and the desired final SOC for scenario $I$ are given in Table IX. Figure 12 summarizes the extra-fuel consumption in [\%] with respect to scenario $I$. The various scenarios are compared with the same desired final $\operatorname{SOC}\left(\xi_{\text {ref }}\right)$ and with the same final time $t_{f}$.

TABLE IX

RESUlTS OF SCENARIO $I$ : HYBRID CASE

\begin{tabular}{|l|c|c|}
\hline & $\xi_{\text {ref }}[\%]$ & Fuel consumption [g] \\
\hline ECE-15 & 60 & 86.4 \\
\hline A. Urban & 60 & 89.3 \\
\hline A. Rural & 60 & 554 \\
\hline WLTC & 60 & 699.7 \\
\hline EUDC & 60 & 238.6 \\
\hline
\end{tabular}

Extra-fuel consumption [\%]

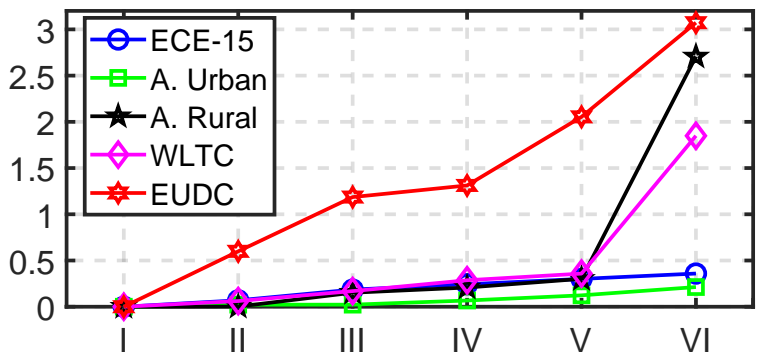

Fig. 12. Extra-fuel consumption [\%] with the same $\operatorname{SOC}\left(t_{f}\right)$ versus scenarios of Table IV: Hybrid case. The various scenarios are compared with the same desired final SOC $\left(\xi_{\text {ref }}\right)$ and with the same final time $t_{f}$.

The extra-fuel consumption increases when the look ahead distance $D_{0}$ decreases, and its maximum value is less than $3.1 \%$ compared to scenario $I$ (the sub-optimality remains in the same order of magnitude as the conventional case). Based on the nature of the trip, two cases are distinguished:
- Driving cycles with a low mean speed value (the ECE15 and the Artemis Urban): the sub-optimality is less than $0.5 \%$ for all the scenarios considered.

- Driving cycles with a high mean speed value (the Artemis Rural, the WLTC and the EUDC): scenario $V$ for $D_{0}=1 \mathrm{~km}$ and $D_{f}=0.26 \mathrm{~km}$, where the suboptimality is less than $2 \%$, is a good choice.

The vehicle speed and the SOC trajectories for the A. Rural driving cycle are given as a representative example in Figures 13 and 14.

- The speed trajectories are very similar except for the case where $D_{0}=0.5 \mathrm{~km}$. Small drops in the vehicle speed appear. These drops are related to the speed freeconstraint at the end of each segment.

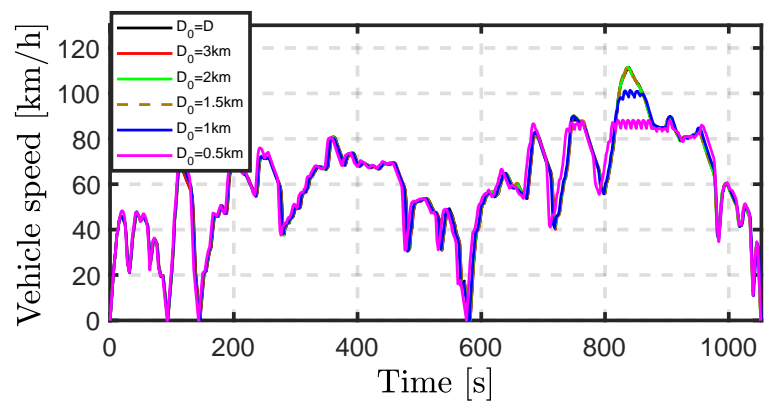

Fig. 13. Speed versus time for the A. Rural: Hybrid case.

- The SOC trajectories are quite different. When the driving cycle is known in advance, the SOC variation is the largest $(16 \%$ between the maximum and the minimum values of the SOC). When the look-ahead distance decreases, the maximum SOC variation decreases. This behavior is due to the constraint (16) on the SOC at the end of each segment.

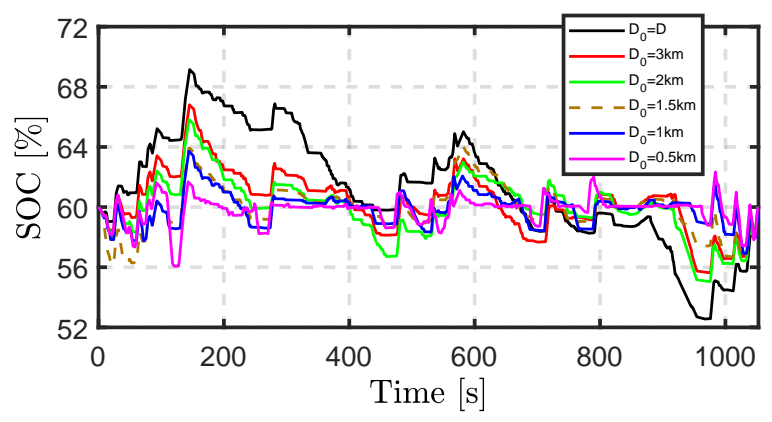

Fig. 14. The SOC versus time for the A. Rural: Hybrid case.

To summarize, Figure 15 shows the inputs, the outputs and the parameters of the optimization algorithm (for all the architectures).

- $\beta$ is estimated based on the mean speed value of the trip as explained in Section II-B.3 by equation (13). The information about the mean speed can be provided by the GPS or any other source. The results are promising with an acceptable error on the final time of $4 \%$. 


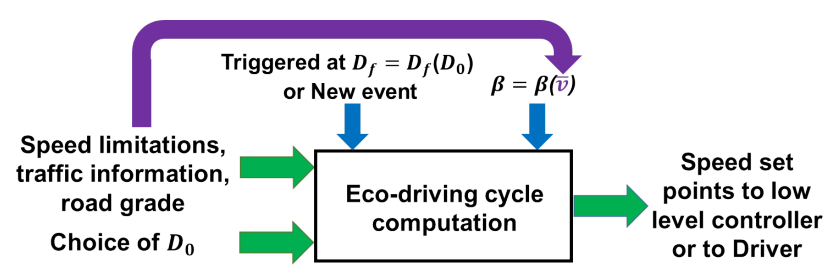

Fig. 15. Predictive Eco-driving algorithm: inputs and outputs.

- $D_{0}$ is chosen based on the nature of the driving cycle and depending on the reliability of the available information: urban, extra-urban and highway. The study conducted in Sections IV and V shows that a look-ahead distance of $0.3-0.5 \mathrm{~km}$ for urban trips and of $1-1.5 \mathrm{~km}$ for the highway preserves the optimality.

- $D_{f}$ controls the launch of the algorithm. Its value is chosen to find a good trade-off between the optimality of the solution and the computation time. The choice of $D_{f}$ can be related to the look-ahead distance $D_{0}$ as explained in Section III-B. The algorithm can also be launched if the traffic and speed constraints change suddenly, if other barriers appear (persons crossing the road) and if there is a difference between the real speed and the set point.

- The outputs of the algorithm are the vehicle speed and the gear-box ratio set points to the low level controllers or to the driver.

\section{CONCLUSION}

The computation of eco-driving cycles for electric, conventional and hybrid electric vehicles using receding horizon control was addressed and formulated as an optimal control problem. The proposed method is based on dynamic programming. A first objective was to investigate the choice of the optimization frequency in order to find a trade-off between the optimality of the solution and the computation time of the algorithm. A relation between the optimization frequency and the look-ahead distance was identified and validated numerically.

Once $D_{f}$ had been optimized, a second objective was to study the impact of the look-ahead distance on the computation of eco-driving cycles. The result is that, for the three architectures under consideration, in the case of urban trips (mean speed values less than $40 \mathrm{~km} / \mathrm{h}$ ), a look-ahead distance of $0.3-0.5 \mathrm{~km}$ leads to a sub-optimality in the energy saving less than $0.6 \%$ compared to the global solution. For high mean speed value trips, a look-ahead distance of $1-1.5 \mathrm{~km}$ can be used as the induced sub-optimality is less than $1 \%$. Moreover, the computation times are relatively small: less than $1.2 \mathrm{~s}$ for a conventional vehicle and less than $0.5 \mathrm{~s}$ for the electric case. These results represent a first step toward a real-time implementation of the proposed algorithm in an Engine Control Unit (ECU).

\section{REFERENCES}

[1] N. Petit and A. Sciarretta, "Optimal drive of electric vehicles using an inversion-based trajectory generation approach," 18th IFAC World Congress, vol. 18, pp. 14519-14 526, 2011.

[2] V. Monastyrsky and I. Golownykh, "Rapid computation of optimal control for vehicles," Transportation Research Part B, vol. 27, pp. 219-227, 1993.

[3] S.-Y. Kim, D.-J. Shin, and H.-J. e. a. Yoon, "Development of ecodriving guide system," In SAE asia pacific automotive engineering conference, pp. 1636-1641, 2011.

[4] F. Mensing, "Optimal energy utilization in conventional, electric and hybrid vehicles and its application to eco-driving," Ph.D. dissertation, INSA Lyon, 2013.

[5] W. Dib, A. Chasse, P. Moulin, A. Sciarretta, and G. Corde, "Optimal energy management for an electric vehicle in eco-driving applications," Control Engineering Practice, vol. 29, pp. 299-307, 2014.

[6] D. Maamria, K. Gillet, G. Colin, Y. Chamaillard, and C. Nouillant, "Optimal eco-driving for conventional vehicles: simulation and experiment," 20th World Congress of IFAC, 2017.

[7] T. J. Daun, D. G. Braun, C. Frank, S. Haug, and M. Lienkamp, "Evaluation of driving behavior and the efficacy of a predictive eco-driving assistance system for heavy commercial vehicles in a driving simulator experiment," 16th International IEEE Conference on Intelligent Transportation Systems, 2013.

[8] E. Ozatay, U. Ozguner, J. Michelini, and D. Filev, "Analytical solution to the minimum energy consumption based velocity profile optimization problem with variable road grade ?" 19th World Congress, pp. 7541-754, 2014.

[9] E. Hellstrom, J. Aslund, and L. Nielsen, "Design of an efficient algorithm for fuel-optimal look-ahead control," Control Engineering Practice, vol. 18, pp. 1318-1327, 2010.

[10] F. Mensing, E. Bideaux, R. Trigui, J. Ribet, and B. Jeanneret, "Ecodriving: an economic or ecologic driving style?" Transportation Research Part C: Emerging Technologies, vol. 38, pp. 110-121, 2014.

[11] A. Sciarretta, G. D. Nunzio, and L. L. Ojeda, "Optimal ecodriving control: Energy-efficient driving of road vehicles as an optimal control problem," IEEE Control Systems Magazine, vol. 35.5, pp. 71-90, 2015.

[12] M. Miyatake, M. Kuriyama, and Y. Takeda, "Theoretical study on ecodriving technique for an electric vehicle considering traffic signals," in Proc. 9th IEEE Int. Conf. Power Electronics Drive Systems, pp. 733-738, 2011.

[13] D. Maamria, K. Gillet, G. Colin, Y. Chamaillard, and C. Nouillant, "On the use of dynamic programming in eco-driving cycle computation for electric vehicles," IEEE MSC, 2016.

[14] H. Bouvier, G. Colin, and Y. Chamaillard, "Determination and comparison of optimal eco-driving cycles for hybrid electric vehicles," European Control Conference, pp. 142-147, 2015.

[15] T. S. Kim, C. Manzie, and R. Sharma, "Two-stage optimal control of a parallel hybrid vehicle with traffic preview," IFAC Proceedings Volumes, vol. 44, pp. 2115-2120, 2011.

[16] T. van Keulen, B. de Jager, D. Foster, and M. Steinbuch, "Velocity trajectory optimization in hybrid electric trucks," in Proc. American Control Conference, pp. 5074-5079, 2010.

[17] E. Hellstrom, M. Ivarsson, J. Aslund, and L. Nielsen, "Look-ahead control for heavy trucks to minimize trip time and fuel consumption," IFAC Proceedings Volumes, 2007.

[18] S. H. M. Wang, W. Daamen and B. van Arem, "Driver assistance systems modeling by model predictive control," 15th International IEEE Conference on Intelligent Transportation Systems, 2012.

[19] B. Passenberg, P. Kock, and O. Stursberg, "Combined time and fuel optimal driving of trucks based on a hybrid model," 2009 European Control Conference (ECC), 2009.

[20] S. T. K. Neiss and T. Connolly, "Predictive speed control for a motor vehicle," United States Patent US 6,990,401 B2, Daimler-Chrysler AG, 2006.

[21] T. Schwickart, H. Voos, J. R. Hadji-Minaglou, and M. Darouach, "An efficient nonlinear model-predictive eco-cruise control for electric vehicles," 2013 11th IEEE International Conference on Industrial Informatics, 2013.

[22] M. Kamal and T. Kawabe, "Eco-driving using real-time optimization," European Control Conference, vol. 21, no. 3, pp. 831-841, 2015.

[23] T. Levermore, M. N. Sahinkaya, Y. Zweiri, and B. Neaves, "Real-time velocity optimization to minimize energy use in passenger vehicles," Energies, 2017. 
[24] L. Guzzella and A. Sciarretta, Vehicle propulsion systems. Springer, 2013.

[25] F. Badin, Hybrid Vehicles. Editions TECHNIP, 2013.

[26] P. Malisani, "Dynamic control of energy in buildings using constrained optimal control by interior penalty," Ph.D. dissertation, Ecole Nationale Supérieure des Mines de Paris, 2012.

[27] D. Bertsekas, Dynamic programming and optimal control. Athena Scientific, 2012.

[28] A.-E. Bryson and Y.-C. Ho, Applied optimal control. Ginn and Company: Waltham, MA, 1969

[29] A. Michel, "The ARTEMIS European driving cycles for measuring car pollutant emissions," Science of The Total Environment, vol. 334-335, pp. 73-84, 2004

[30] M. Back, M. Simons, F. Kirschaum, and V. Krebs, "Predictive control of drivetrains," IFAC 15th triennial world congress, Spain., 2002.

[31] S. Qin and T. Badgwell, "A survey of industrial model predictive control technology," Control engineering practice, vol. 11, pp. 733 764, 2003.

[32] M. Debert, G. Colin, Y. Chamaillard, L. Guzzella, A. Ketfi-cherif, and B. Bellicaud, "Predictive energy management for hybrid electric vehicles - prediction horizon and battery capacity sensitivity," Advances in Automotive Control IFAC, Munich, Germany., 2010.

[33] D. Maamria, K. Gillet, G. Colin, Y. Chamaillard, and C. Nouillant, "Which methodology is more appropriate to solve eco-driving optimal control problem for conventional vehicles?" IEEE MSC, 2016.

[34] P. Michel, A. Charlet, G. Colin, Y. Chamaillard, G. Bloch, and C. Nouillant, "Optimizing fuel consumption and pollutant emissions of gasoline-hev with catalytic converter," Control Engineering Practice, 2015.

[35] A. Simon, P. Michel, D. Nelson-Gruel, and Y. Chamaillard, "Gasolinehev equivalent consumption and pollutant minimization strategy," IEEE Vehicle Power and Propulsion Conference, 2015.

[36] D. V. Ngo, T. Hofman, M. Steinbuch, and A. F. A. Serrarens, "An optimal control-based algorithm for hybrid electric vehicle using preview route information," Proceedings of the 2010 American Control Conference, pp. 5818-5823, 2010.

[37] A. Sciarretta, M. Back, and L. Guzzella, "Optimal control of parallel hybrid electric vehicles," IEEE Transactions on Control Systems Technology, vol. 12, pp. 352-363, 2004.

[38] L.-S. Pontryagin, V.-G. Boltyanskii, R.-V. Gamkrelidze, and E.-F Mishchenko, The mathematical theory of optimal processes. Interscience Publishers John Wiley \& Sons, Inc. New York, London, 1962.

[39] G. Paganelli, S. Delprat, T.-M. Guerra, J. Rimaux, and J.-J. Santin, "Equivalent consumption minimization strategy for parallel hybrid powertrains," IEEE Vehicular Technology Conference, pp. 2076-2081, 2002.

[40] L. Serrao, S. Onori, and G. Rizzoni, "ECMS as a realization of Pontryagin's minimum principle for HEV control," in Proc. of the American Control Conference, pp. 3964-3969, 2009.

[41] N. Kim, S. Cha, and H. Peng, "Optimal equivalent fuel consumption for hybrid electric vehicles," IEEE Transactions on Control Systems Technology, vol. 20, no. 3, pp. 817-825, 2012.

[42] S. Onori and L. Serrao, "On adaptive-ECMS strategies for hybrid electric vehicles," Proc. of the International Scientific Conference on Hybrid and Electric Vehicles, pp. 1-7, 2011.

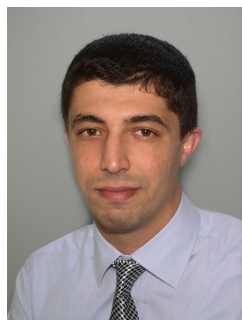

Djamaleddine Maamria is an engineer in the «emissions, $\mathrm{CO}_{2}$, control and optimization for hybrid powertrains» team at the PSA Peugeot Citroën Group. He received the degree in engineering from the National Polytechnic School of Algiers, Algeria in 2011, the Master's degree in automatic control from École Normale Supérieure de Cachan, France in 2012, and the Ph.D. degree in Applied Mathematics and Automation in 2015 from l'École nationale supérieure des Mines de Paris, France. His research interests include control and optimization, particularly for hybrid powertrains.

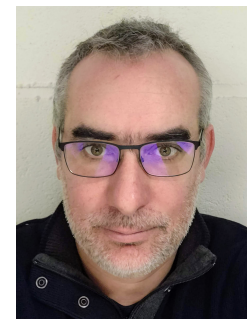

Kristan Gillet received the Global Automotive Engineering master degree from the University of Orláns, France, in 2008. Since 2009, he has been research engineer with the PRISME Laboratory of the University of Orléans. His research interests include energy management of powertrains, internal combustion engine modeling and control $\mathrm{He}$ also manages the PRISME lab experimental facilities (e.g. engine test benches) and teaches in school of engineering of the University of Orléans (Polytech).

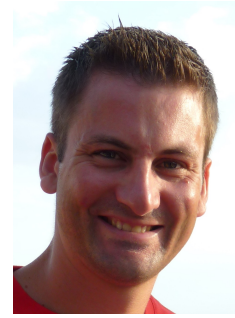

Guillaume Colin received the degree in engineering from the École Supérieure des Sciences et Technologies de l'ingénieur de Nancy, France, in 2003 and the Master's degree in automatic control and the Ph.D. degree in energetics in 2006, as well as the Habilitation to conduct research in 2013, from the University of Orléans, France. He is actually Associate Professor with the University of Orléans. Since 2003, he has been with the PRISME Laboratory of the University of Orléans. He teaches in school of engineering of the University of Orléans (Polytech), where he is the Head of the Department of Technologies for Energy, Aerospace, and Engines. His research interests include powertrains and automatic control, particularly nonlinear control and optimization.

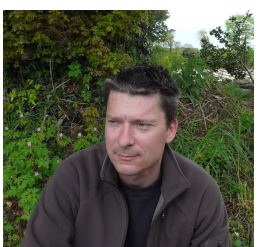

Yann Chamaillard received the Ph.D. degree in automatic control from the University of Mulhouse, France, in 1996. In 2008, he became a Full Professor with the University of Orléans, France. $\mathrm{He}$ is the coordinator of Modeling, Optimization, and Control for the research group ECM of the PRISME Laboratory. His research interests include robust and predictive control, optimization, identification, modeling for control, engine control, and energy management for hybrid vehicles. Pr. Chamaillard has been a Vice Chair of the Technical Committee on automotive control of the International Federation of Automatic Control (TC 7.1) since 2008 and a Cochair of the "Automatique and automobile" French Group of the GDR MACS since 2003.

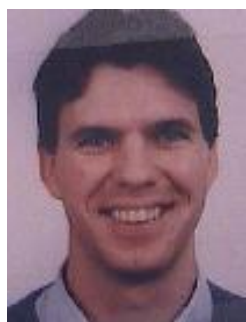

Cédric Nouillant is leading the team «Emissions and Energy, Control and Optimization» for alternative powertrains at the Research, Innovation and Advanced technologies Division of the PSA Peugeot Citroën Group. After a PhD on Automation in Bordeaux in 2002, he joined the group as mechatronic engineer. He spent research on different innovation projects. 